\title{
ENSINO DA GEOMETRIA NO ENSINO FUNDAMENTAL: UM PROBLEMA SISTÊMICO
}

\author{
Débora de Sales Fontoura da Silva Frantz; Vanilde Bisognin²
}

\section{RESUMO}

O presente artigo é parte de uma pesquisa bibliográfica do projeto de tese desenvolvido no Programa de Pós-Graduação em Ensino de Ciências e Matemática da Universidade Franscicana, cujo objetivo consiste em investigar alguns fatores que nos permitam enxergar as dificuldades apresentadas no ensino de geometria no Ensino Fundamental como um problema sistêmico. Para tanto, buscamos informações nos documentos do Programme for International Student Assessment PISA, bem como em relatórios fornecidos pelo Inep, dos quais mostraremos resultados do desempenho médio em Matemática e os níveis de proficiência de alunos participantes do Brasil e da OCDE (Organização para a Cooperação e Desenvolvimento Econômico). Esses resultados representam indicativos que nos permitem deduzir que não é de hoje os obstáculos no ensino de geometria no Ensino Fundamental, pois não é somente um problema citado por alguns docentes de forma isolada, mas, sim, é um problema típico do mundo em que vivemos.

Palavras-chave: Pesquisa; Educação Matemática; PISA; Desempenho.

Eixo Temático: Educação, Cultura e Comunicação (ECC)

\section{INTRODUÇÃO}

Para entender a importância da problemática acerca do ensino da geometria no Ensino Fundamental como um problema sistêmico, convém aqui destacar que, essa é uma das categorias de conteúdos matemáticos que merece muito a nossa atenção, pois sua relevância aparece como uma dificuldade típica do mundo em que vivemos.

\footnotetext{
1 Doutoranda do Programa de Pós-graduação em Ensino de Ciências e Matemática - Universidade Franciscana. E-mail: debora_frantz@hotmail.com

2 Docente do Programa de Pós-graduação em Ensino de Ciências e Matemática. Universidade Franciscana.E-mail:vanilde@ufn.edu.br
} 
Mas, antes de tudo, é considerável elucidar a seguinte pergunta: como esse assunto veio à tona neste projeto? Como resposta, ressalta-se que essa temática veio à lume a partir do momento em que questionamos alguns docentes, participantes do projeto de tese, acerca de uma problemática que os angustie, ou seja, algum conteúdo que os mesmos apresentam mais dificuldade em transmitir aos seus alunos. Como resposta quase que unânime, a Geometria foi citada como a que eles apresentam maior dificuldade para transmitir aos seus alunos.

No entanto, nos questionamos: será que essa problemática citada pelos docentes de Matemática participantes é um problema sistêmico? Primeiramente, sistêmico, deriva da palavra sistema, que é o conjunto que forma determinado grupo, e sistêmico são todas as interligações necessárias que permitem enxergar o sistema como um todo, de uma forma mais ampla, desde os fatores críticos que favorecem até aqueles que podem ser considerados uma ameaça ao sistema e comprometer determinado grupo. Então, cabe a nós tentar aqui investigar alguns fatores que nos permitiram enxergar que essa problemática apresentada pelos docentes está muito além de ser apenas um problema isolado desses docentes, e, sim, ser um problema que vem ocorrendo com mais docentes, com mais escolas, mais municípios, mais estados e também com mais países, obtendo, assim, uma visão de diversos elementos e interações que interligam o sistema de ensino da geometria com a dificuldade apresentada, para que seja possível ocorrer mudanças.

\section{METODOLOGIA}

Para tanto, optamos em buscar informações nos documentos do Programme for International Student Assessment (Pisa), bem como em relatórios fornecidos pelo Inep, com informações relativas às aplicações ocorridas nas edições (2018 e 2012), das quais iremos mostrar os resultados do desempenho médio em Matemática de alunos participantes, bem como os níveis de proficiência, pontuação mínima e porcentagem de alunos participantes do Brasil e da $\operatorname{OCDE}^{3}$ (Organização para a

\footnotetext{
${ }^{3}$ A OCDE (Organização para a Cooperação e Desenvolvimento Econômico) também atua no setor educacional e o seu principal órgão é o Comitê de Políticas Educacionais (Education Policy Committe). O órgão foi criado no ano de 2007, a fim de coordenar as ações que permeiam a educação, contribuindo para que os países consigam promover políticas públicas que garantam uma
} 
Cooperação e Desenvolvimento Econômico) em cada nível. Além disso, destacaremos o resultado dos alunos brasileiros participantes no estado do Rio Grande do Sul na avaliação de Matemática por nível de proficiência e a pontuação média por dependência administrativa (Municipal e estadual) em relação à média do Brasil e da OCDE, bem como o desempenho desses alunos na categoria de conteúdo, espaço e forma, na disciplina de Matemática.

Contudo, mostraremos o que relatam os autores Lorenzato $(1995,2015)$ e Pavanello (1989) acerca dessa problemática, visto que os mesmos desenvolveram pesquisas associadas ao ensino da geometria na escola e o seu abandono. Antes de iniciar, cabe aqui ressaltar que a intenção da pesquisa não infere no debate da validade dessas avaliações, uma vez que elas não trazem de forma isolada apenas o desempenho dos alunos no ramo da Geometria, mas, sim, evidencia os resultados de maneira ampla na disciplina de Matemática.

\section{RESULTADOS E DISCUSSÕES}

Dessa forma, destacamos que os resultados divulgados da última edição do Pisa 2018, nomeado no Brasil de Programa de Avaliação Internacional de Estudantes, soou como um alerta de que ainda persistem grandes desafios para a educação básica do Brasil. O Pisa "visa avaliar a capacidade que os alunos de 15 anos de diferentes países/economias têm para mobilizar conhecimentos nos domínios da matemática, da leitura e das ciências e responder a situações comuns da vida quotidiana" (PORTUGAL, 2013, p. 1). O documento de avaliação, Brasil no Pisa, é realizado a cada três anos pela Organização para a Cooperação e Desenvolvimento Econômico (OCDE) e contém informações sobre o desempenho e a aprendizagem de alunos de 15 anos de idade, pelo fato destes estudantes estarem perto de concluir sua educação básica e possuírem os requisitos educacionais básicos à avaliação.

Segundo o Anuário Brasileiro de Educação Básica de (2019, p. 74), o Pisa passou a ser, no ano 2000, a principal referência internacional em avaliação de qualidade em educação. No entanto, quem coordena a aplicação do Pisa no Brasil é 
o Instituto Nacional de Estudos e Pesquisas Educacionais Anísio Teixeira (INEP) e, segundo o Relatório Brasil no PISA (2018, p. 20), o estudo realizado pelo Pisa "permite ao Brasil aferir conhecimentos e habilidades dos estudantes (...), pois o desafio é refletir a situação de instituições públicas e privadas, estados, regiões e estudantes com diferentes níveis socioeconômicos" (REVISTA NOVA ESCOLA ${ }^{4}$, 2018). No pisa 2018 são apresentados os resultados do desempenho de alunos dos 37 países membros da OCDE, além de 42 países/economias parceiras, totalizando 78 países participantes no Pisa 2018. A pontuação média, no caso particular da Matemática, nos países da OCDE, foi de 489 pontos e os alunos brasileiros que participaram dessa avaliação ficaram nas últimas posições nessa edição, ocupando a $70^{\text {a }}$ colocação, com média de desempenho de 384 pontos, média essa bem inferior a da OCDE, conforme podemos observar na Figura 1.

FIGURA 1 - Posição e pontuação média dos países participantes do ranking mundial em Matemática no PISA 2018.

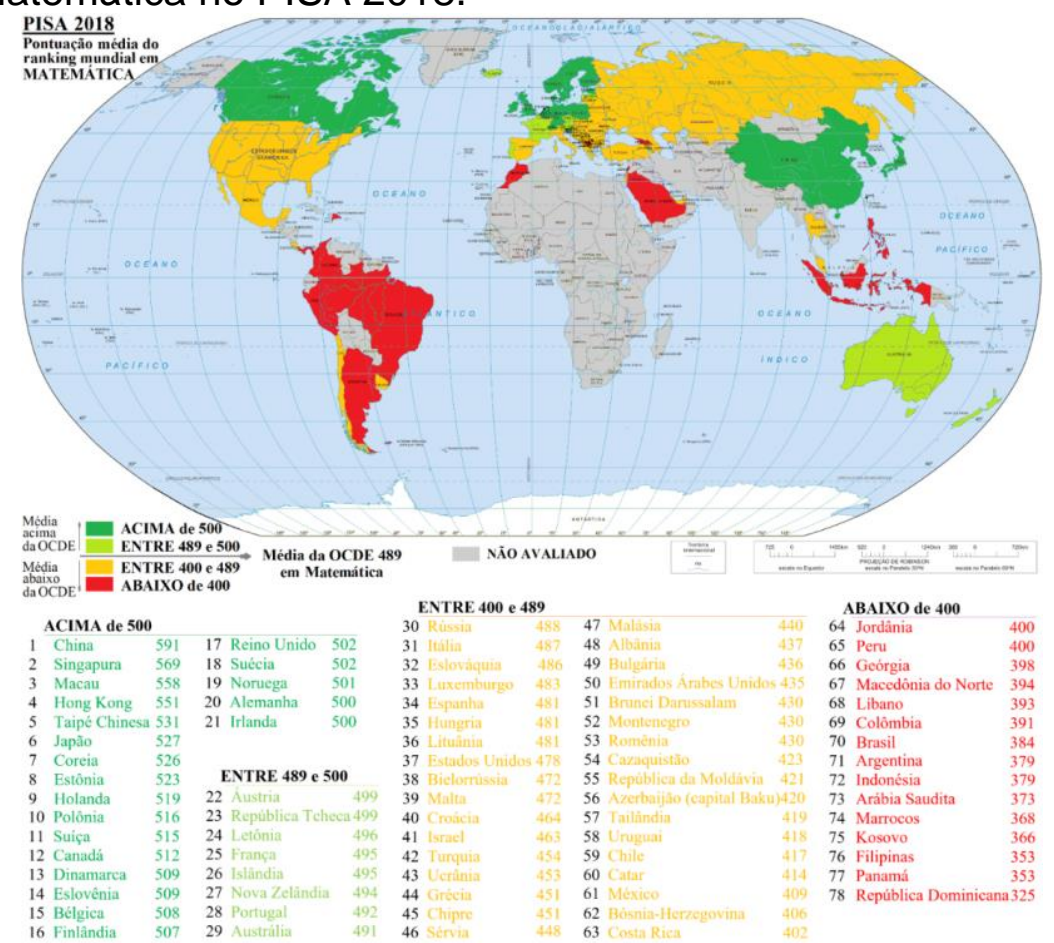

Fonte: Elaborada e editada pela autora, com base em dados da OCDE e PISA (2018) e no Mapamúndi político com a identificação dos países do IBGE. Disponível em: https://atlasescolar.ibge.gov.br/images/atlas/mapas_mundo/mundo_planisferio_politico_a3.pdf.

\footnotetext{
${ }^{4}$ Artigo da Revista Nova Escola. Disponível em: <https://novaescola.org.br/conteudo/18738/pisa-2018-como-osresultados-podem-contribuir-para-a-melhoria-da-educacao-no-brasil>. Acesso em: 28 jan. 2021
} 
A Figura 1 apresenta o mapa mundi e a lista dos 78 países participantes do Pisa 2018, ordenada por ordem crescente de acordo com a pontuação média alcançada. O mapa foi pintado pela pesquisadora e dividido com 4 cores, de acordo com a diferença das pontuações médias do ranking mundial de desempenho dos alunos na avalição de Matemática de cada país em relação à pontuação média da OCDE. As cores verde, escuro e verde-claro destacam os países que ficaram com média superior a da OCDE, e as cores laranja e vermelho destacam os países que ficaram com média inferior a da OCDE. Inicialmente, dividu-se os países em 3 grupos, os com média abaixo de 400 pontos, os com média entre 400 e 500 pontos e os com média acima de 500 pontos. No entanto, como a média da OCDE é 489 pontos, neste caso, os grupos de países que tiveram médias entre 400 e 500 pontos foram subdivididos em dois grupos, os países que foram pintados na cor verde-claro são os que ficaram com média acima da OCDE, porém, são médias que não são significativamente muito diferentes da média da OCDE, e os países que foram pintados na cor laranja são os que ficaram com média abaixo da estipulada pela OCDE. Entretanto, são médias que não são muito diferentes da determinada pela OCDE. Já os países pintados na cor verde-escuro são os que agregaram pontuações médias significativamente bem superiores à média da OCDE, acima de 500 pontos, e, por fim, os países que foram pintados na cor vermelho são os que obtiveram pontuações significativamente muito inferior da média da OCDE.

Como podemos observar na Figura 1, dentre os países pintados na cor verdeescuro, a China lidera o ranking em primeiro lugar, com média de 591 pontos. Já na América do Sul, todos os países participantes ficaram com médias abaixo da média da OCDE, e estão destacados no mapa nas cores laranja e vermelho. O país mais bem colocado na categoria Matemática é o Uruguai, com 418 pontos, aparecendo na $58^{\text {a }}$ posição do ranking geral, seguido de Chile, com 417 pontos e na $59^{a}$ posição, e Costa Rica, com 402 pontos, na 63a posição. O Brasil, destacado na cor vermelha, aparece nas últimas posições, ocupando a $70^{\circledR}$ posição, com uma pontuação média de 384 pontos, superando apenas a Argentina, com 379 pontos, na $71^{\text {a }}$ posição, e o Panamá, com 353 pontos, na $77^{a}$ posição do ranking geral. 
$\mathrm{Na}$ avaliação do Pisa, os alunos são distribuídos em 6 (seis) níveis de proficiência em cada uma das 3 (três) áreas avaliadas (Leitura, Matemática e Ciências). A porcentagem de alunos em cada país que alcançam bons níveis de proficiência indica quão bem esses países conseguem favorecer a sublimidade em seus sistemas educativos. Os níveis mais elevados são $\circ 5$ e $\circ 6$, onde se encontram os alunos com melhor desempenho. O nível 2 é considerado, segundo a OCDE, "o nível básico de proficiência que se espera de todos os jovens, a fim de que possam tirar proveito de novas oportunidades de aprendizagem e participar plenamente da vida social, econômica e cívica da sociedade moderna em um mundo globalizado" (PISA, 2018, p. 108). Contudo, esse é o nível mínimo adequado para a plena participação na vida social, econômica e civil, sendo que os alunos que estão abaixo desse nível 2 são considerados com baixo desempenho na avaliação, conforme descrição dos seis níveis de proficiência em Matemática considerados no PISA 2018, no qual, consta a pontuação mínima e a porcentagem de alunos participantes do Brasil e da OCDE em cada nível. Nessa porcentagem, consta que aproximadamente $31,8 \%$ dos alunos alcançaram pelo menos o nível 2 ou acima desse nível de proficiência em Matemática. O nível 2, que é considerado pela OCDE como básico, somente é atingido a partir da pontuação média de 420 pontos de desempenho na avalição em Matemática no Pisa. Como os alunos brasileiros não obtiveram mais do que 384 pontos, o Brasil, neste caso, fica classificado no nível 1 de proficiência na escala em Matemática. Dos alunos avaliados, 68,1\% se encontram nos níveis 1 e abaixo de 1 , o que revela, segundo os parâmentos na OCDE, que esses alunos não possuem nível básico no conhecimento de Matemática. Esses alunos, conforme os resultados do PISA 2018, conseguem no mínimo interpretar e reconhecer, sem instruções diretas, como uma situação (simples) pode ser representada matematicamente.

Diante disso, nota-se que a situação dos alunos brasileiros em relação à Matemática mostra-se preocupante, principalmente pelo fato de apresentar uma porcentagem bastante elevada de alunos no nível abaixo de 1 (41\%), porcentagem essa bem superior à da OCDE, que é $9,1 \%$ de proficiência na escala em Matemática. Nesse nível abaixo de 1, o PISA apresenta poucas tarefas que ajudam 
a descrevê-lo. No entanto, nesse nível "é esperado que os alunos com proficiência menor que 358, equivalente ao nível abaixo de 1, consigam realizar algumas tarefas matemáticas diretas e fáceis" (PISA, 2018, p. 110).

Além do mais, para que possamos ter um resultado com mais detalhes sobre o desempenho dos alunos brasileiros no Pisa 2018, o próprio relatório de avaliação apresenta uma avaliação das diferenças regionais nos resultados da avaliação de Matemática dos alunos por nível de proficiência e também traz uma análise do desempenho geral por dependência administrativa (particular, federal, estadual e municipal). No Gráfico 1, mostramos o resultado apresentado pelos alunos brasileiros participantes no estado do Rio Grande do Sul, no qual podemos observar que apenas $18 \%$ dos alunos conseguiram alcançar o nível 3 de proficiência em Matemática ou acima. No nível 2, nível que a OCDE estabelece como necessário para que o estudante possa exercer plenamente sua cidadania, considerado como o básico, observamos que apenas $22 \%$ dos alunos participantes alcançaram esse nível.

Gráfico 1: Resultado dos alunos brasileiros participantes no estado do Rio Grande do Sul na avaliação de Matemática por nível de proficiência.

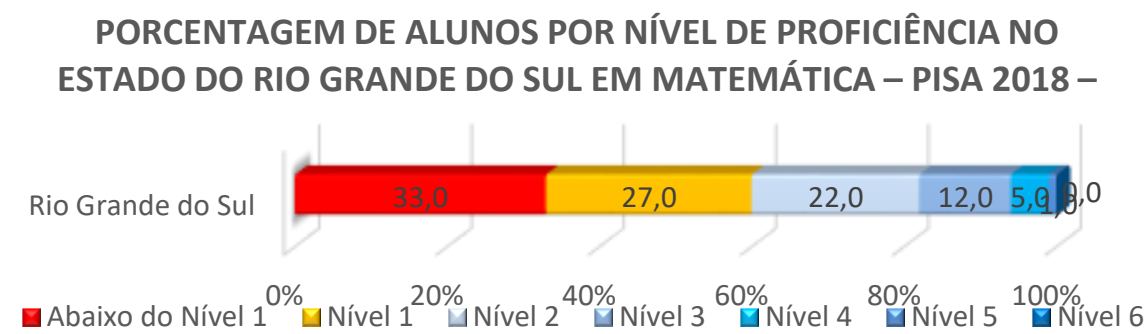

Fonte: Elaborado pela autora, com base em dados da OCDE e relatório do Brasil no PISA (2018).

O Gráfico 1 mostra uma situação preocupante também para o estado do Rio Grande do Sul, pois revela que $60 \%$ dos alunos avaliados no estado encontram-se nos níveis 1 e abaixo de 1, o que indica, segundo os parâmentos na OCDE, que esses alunos não possuem nível básico no conhecimento de Matemática.

Na pontuação média de proficiência em Matemática dos alunos brasileiros por dependência administrativa, o relatório de avaliação do Pisa 2018 apresentou a média de 314 pontos dos alunos das escolas públicas municipais e a média de 374 
das escolas públicas estaduais participantes, o que ilustra uma diferença estatisticamente significativa, muito abaixo da média da OCDE, 489.

Cabe aqui ressaltar que em cada edição do PISA é dada ênfase maior a uma das 3 (três) áreas avaliadas (Leitura, Matemática e Ciências), sempre em alternância, pois, segundo Relatório Brasil no (PISA 2018, 2019, p.15), "isso significa que os estudantes responderam a um maior número de itens no teste dessa área do conhecimento". Nesse caso, ressaltamos que, na última edição do Pisa no ano de 2018, o foco foi a leitura, na qual não estão disponíveis médias ou porcentagens sobre o desempenho dos alunos nas categorias de conteúdos Matemáticos, no entanto, tais porcentagens são apresentadas na edição de 2012, em que o foco principal foi a Matemática. Entre as quatro categorias de conteúdos matemáticos (variações e relações; espaço e forma; quantidade; incerteza e dados) que foram avaliados nessa edição, a área com desempenho mais crítico apresentada foi a de Espaço e Forma, na qual mostra que $70,9 \%$ dos alunos brasileiros avaliados estão no nível 1 e abaixo de 1 nessa categoria, conforme observamos no Gráfico 2.

Gráfico 2 - Resultado brasileiro na categoria de conteúdo, espaço e forma, na disciplina de matemática por nível no pisa 2012.

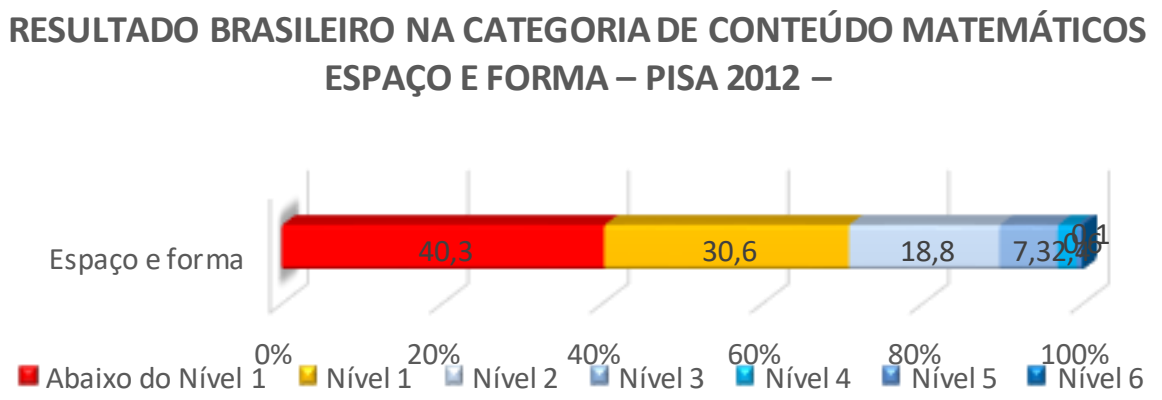

Fonte: Elaborado pela autora, com base em dados da OCDE disponíveis no relatório nacional PISA 2012, resultados brasileiros. Disponível em: https://download.inep.gov.br/acoes_internacionais/pisa/resultados/2014/relatorio_nacional_pisa_2012 _resultados_brasileiros.pdf. Acesso em: 28 jan. 2021.

Esse resultado apresentado na categoria de conteúdos matemáticos, espaço e forma gera muita preocupação, pois, conforme o Pisa (2018, p. 103), essa categoria "envolve compreender a noção de perspectiva, a criação e a leitura de mapas, a transformação de formas (com e sem uso de tecnologias), a interpretação de vistas de cenas tridimensionais a partir de diferentes perspectivas, e a construção 
de representações de formas e, neste caso, esse resultado mostra que os alunos brasileiros avaliados não conseguiram desenvolver tais competências". No entanto, segundo a edição Pisa no ano de 2012, especifica que,

Esta subárea compreende uma ampla gama de fenômenos que são encontrados em vários lugares e no mundo físico e visual: padrões; propriedade dos objetos; posição e orientação; representação dos objetos; codificação e decodificação de informação visual; interação dinâmica com formas reais, bem como com suas representações. A geometria pode ser considerada um fundamento para Espaço e Forma, mas essa categoria vai além do conteúdo tradicional da geometria, utilizando recursos de outras áreas da matemática, como visualização espacial, medida e álgebra. (OCDE, 2012, p. 33).

No portal do Ministério da Educação e do Desporto (MEC) foi publicado que a média em Matemática está entre as menores do Pisa e descreve que a categoria de conteúdo com os maiores valores no índice de desempenho foi a de espaço e forma pois,

[...] esta subárea da avaliação de matemática envolve uma diversidade de propriedades encontradas em vários lugares no mundo físico e visual. Trabalha-se, por exemplo, com as propriedades das figuras geométricas, como o perímetro ou a área, e as características das figuras espaciais entre outras. A interação dinâmica com formas reais, bem como com suas representações, mostrou-se um conteúdo mais difícil e trabalhoso para os estudantes. (BRASIL. MEC, 2019).

No entanto, como a categoria espaço e forma é considerada, segundo o MEC, a de menor valor no índice de desempenho no Pisa, em virtude de os alunos brasileiros apresentarem baixo desempenho na disciplina de Matemática e média baixa. Neste caso, o Gráfico 2, acima, mostra perfeitamente esse baixo desempenho, pois o Brasil apresentou, aproximadamente 18,8\%, dos alunos participantes que conseguiram atingir o nível 2 e apenas 10,4\% dos alunos conseguiram obter pontuação no nível 3 ou acima desse nível na categoria de conteúdos matemáticos espaço e forma. Contudo, essa situação revela-se preocupante, principalmente pelo fato de mostrar que 40,3\% dos alunos brasileiros avaliados ficaram no nível abaixo de 1, que são considerados pela OCDE, alunos que não possuem nível básico no conhecimento de Matemática.

Dessa forma, após analisar essas porcentagens apresentadas pela avaliação de Matemática do Brasil no Pisa e verificar o baixo desempenho que os alunos brasileiros vem apresentando na categoria de conteúdo Espaço e Forma, logo vem em mente a seguinte questão: será que esses conteúdos, espaço e forma, 
especificamente a geometria, estão sendo contemplados no currículo? E a equipe docente tem a formação adequada para ensiná-los?

Nesse caso, observamos que a escola atualmente é quem desempenha o papel fundamental de transmitir o conhecimento, sendo que, nas últimas décadas, é possível perceber o abandono gradual da Geometria. Decorre que, com a promulgação da Lei de Diretrizes e Bases (LDB no 5692/71), o descaso com a geometria no Brasil se tornou ainda mais evidente nas escolas públicas, pelo fato de as mesmas passarem a ter mais autonomia para selecionar o conteúdo curricular. Contudo, diversos docentes, inseguros em trabalhar com a Geometria, usufruiram desse benefício de decisão e acabaram deixando de lado ou abordando a geometria mais no final do ano letivo, o que, em muitos casos, pela falta de tempo, os impede de cumprir o que é proposto nos planos de ensino, fazendo com que os docentes optem, assim, por deixar a Geometria para o ano letivo seguinte, como afirma Pavanello (1989), em sua dissertação de mestrado, quando observou que,

[...] docentes não dominavam nem o conteúdo (alguns confessavam não haver jamais estudado ou fizeram de modo insatisfatório) nem a maneira de desenvolvê-lo com seus alunos. Dentre aqueles que incluiam geometria entre os tópicos a serem desenvolvidos em sala de aula, muitos afirmavam que, por falta de tempo, não conseguiam chegar a abordá-la nem parcialmente. Quando indagados sobre a época do ano reservada para este assunto, respondiam, invariavelmente, ser o último bismestre, ou na melhor das hipóteses, o último trimestre do ano letivo, o que parecia indicar que, conscientemente ou não, a falta de tempo estava sendo usada como desculpa para a não realização do trabalho com geometria. (PAVANELLO, 1989, p. 6)

Apesar disso, Lorenzato (1995) ressalta que são inúmeras as causas para esse descaso e abandono da geometria nas escolas brasileiras, apontando que uma delas é "que muitos professores não detêm os conhecimentos geométricos necessários para realização de suas práticas pedagógicas" (LORENZATO, 2015, p. 3). Dessa forma, não somente nas avaliações de desempenho, mas no cotidiano, no ensino e na aprendizagem de nossos alunos a aprendizagem da geometria se faz necessária ao desenvolvimento do mesmo e é fundamental, no entanto, os resultados obtidos nessas avaliações não são nada agradáveis. Segundo Passos (2000), essas avaliações de desempenho realizadas, principalmente as que mostram o desenvolvimento da geometria em sala de aula, tem revelado que, 
[...] as avaliações sobre o desempenho dos estudantes em Matemática e também em geometria, realizado por órgãos responsáveis pela educação dos Estados Brasileiros, ou diretamente pelo Ministério de Educação (MEC), tem demonstrado uma ausência de conexão entre as propostas de ensino elaboradas pelos órgãos governamentais e os resultados constatados na escola. (PASSOS, 2000, p.78).

\section{CONCLUSÃO}

Esses resultados representam indicativos que nos permitem deduzir que não é de hoje que obstáculos na Educação Matemática ocorrem na prática, nos anos finais do Ensino Fundamental. Essas são apenas algumas informações que, nos fazem refletir sobre a necessidade de apoio aos docentes que ensinam Matemática nos anos finais do Ensino Fundamental, bem como seus alunos. Como vimos, o ensino de geometria vem sendo muitas vezes deixado de lado e o desempenho dos alunos brasileiros apresenta-se abaixo do nível básico exigido, o que nos permite entender um pouco sobre a importância dessa problemática, o estudo de geometria no Ensino Fundamental, problema sistêmico, que merece muito a nossa atenção, pois não é somente um problema citado pelos docentes participantes desta pesquisa de forma isolada. Isto é, não é um problema de apenas alguns docentes, de apenas uma escola, de apenas um município, de apenas um estado, de apenas um país, mas, sim, é um problema que deve ser enfrentado no âmbito da educação.

\section{AGRADECIMENTOS}

O presente trabalho foi realizado com apoio da com da Fundação de Amparo à pesquisa do Estado do RS (FAPERGS) - Código de Financiamento 001.

\section{REFERÊNCIAS}

BRASIL. Ministério da Educação. Avaliação Internacional: Média em Mátemática está entre as menores do Pisa. Brasília: MEC, 2018. Disponível em: http://portal.mec.gov.br/ultimas-noticias/222-537011943/42771-media-emmatematica-esta-entre-as-menores-do-pisa>. Acesso em: 26 fev. 2021. 
Instituto Nacional de Estudos e Pesquisas Educacionais Anísio Teixeira

(INEP). Relatório Brasil no PISA 2018 (versão preliminar). (2019). Brasília-DF Inep/MEC. Disponível em:

https://download.inep.gov.br/acoes_internacionais/pisa/documentos/2019/relatorio_P ISA_2018_preliminar.pdf>. Acesso em: 28 jan. 2021.

Instituto Nacional de Estudos e Pesquisas Educacionais Anísio Teixeira (INEP). Relatório Nacional PISA 1012: resultados brasileiros. São Paulo: Fundação Santillana/Organização para a Cooperação e Desenvolvimento Econômico (OCDE). Disponível em:

https://download.inep.gov.br/acoes_internacionais/pisa/resultados/2014/relatorio_nac ional_pisa_2012_resultados_brasileiros.pdf>. Acesso em: 26 fev. 2021.

CRUZ, P.; MONTEIRO, L. (Org.) Anuário Brasileiro da Educação Básica 2019. São Paulo: Editora Moderna, 2019.

LORENZATO, Sérgio. Como aprendemos e ansinamos geometria. In: LORENZATO, S. Aprender e ensinar geometria. Campinas, SP: Mercado das Letras, 2015. Série Educação Matemática.

- Por que não ensinar Geometria? Educação Matemática em RevistaSBEM, Blumenau-SC, nำ4, p. 03-20, 1ํsem. 1995.

PAVANELLO, Regina M. O abandono do ensino de geometria: uma abordagem histórica. 1989. 195f. Dissertação (Mestrado em Educação) - UNICAMP, Campinas.

PEREIRA, Maria Regina de Oliveira. A geometria escolar: uma análise dos estudos sobre o abandono de seu ensino. Dissertação de Mestrado em Educação Matemática. São Paulo: PUC, 2001.

PORTUGAL. Ministério da Educação. PISA 2012: Portugal, primeiros resultados. Lisboa, 2013. Disponível em: < https://www.dgeec.mec.pt/np4/246/\%7B\$clientServletPath\%7D/?newsld=371\&fileNa me=PISA_Primeiros_Resultados_PORTUGAL.pdf>. Acesso em: 25 fev. 2021. 